\title{
Els gèneres de comunicació científica i el laboratori com a espai didàctic per a l'ensenyament de les Ciències basat en Projectes
}

\author{
José Luis Touron (jtouron@virolai.com) Escola Virolai (Barcelona) \\ Quique Vergara (enriquevergaragasulla@gmail.com) Escola Maristes Champagnat (Badalona) \\ Albert Arcas (aarcas4@xtec.cat) Institut de Sant Pol de Mar (Barcelona) \\ Marcel Costa (mcosta1@xtec.cat) Institut Obert de Catalunya (IOC)
}

Els contextos de Creació del Coneixement Científic són espais clau perquè l'alumnat desenvolupi els procediments $i$ visions epistèmiques de la Ciència, a més d'una apropiació profunda dels models científics. En aquest sentit, l'Aprenentatge Basat en Projectes és una oportunitat per desenvolupar activitats en les que els alumnes aprenguin ciències participant en aquests contextos. Es proposen quatre activitats ABP ubicades en diferents contextos de creació de coneixement científic (congressos científics, ciència ciutadana, indagació al laboratori) i es discuteixen les aportacions que fan aquests diversos gèneres científics a l'ensenyament de les Ciències.

Paraules clau: Congressos científics escolars, Indagació, Ciència ciutadana, Context.

Contexts of construction of scientific knowledge are key places to develop procedural and epistemic aspects of scientific competence, together with a deeper understanding of scientific models. Project-Based Learning is an opportunity to develop learning activities where students learn sciences participating in these contexts. We propose four PBL activities situated in different contexts of construction of scientific knowledge (scientific congresses, citizen science, laboratory inquiry) and we discuss the application of these scientific genera to Science Education.

Keywords: Scholar Scientific Congresses, Inquiry, Citizen Science, Context.

\section{INTRODUCCIÓ}

En l'ensenyament de les ciències, la contextualització és un element important. La contextualització consisteix en presentar a l'alumnat situacions o problemes complexos, la resolució dels quals requereix l'aplicació dels conceptes curriculars que es volen treballar. És conegut que, com més gran és la semblança entre les situacions en què l'alumnat aprèn els continguts i aquelles en què aquests són útils en el món real, major i més fàcil és la transferència dels continguts escolars al món real per part de l'alumnat (Claxton, 1994). Sanmartí (2011) indica l'ús de contextos com una de les millors estratègies per incrementar aquesta transferència.
La contextualització dels continguts es pot realitzar en base a diversos tipus d'escenaris (Grau, 2010), un dels quals són els encàrrecs: propostes que reben els estudiants en les quals se'ls demana el disseny i realització d'alguna activitat, producte o servei. Un d'aquest tipus d'encàrrecs pot ser la Ciència Ciutadana: una pràctica en plena efervescència que implica la participació del públic en les activitats pròpies d'una investigació científica. Els ciutadans contribueixen activament a la recerca ja sigui amb esforç intel-lectual, coneixement, eines o recursos. Els participants proporcionen dades i dispositius experimentals als investigadors, plantegen noves preguntes i creen col-lectivament una nova cultura científica. Aquest tipus d'activitats ofereixen també la possibilitat de treballar contextos i gèneres 
lingüístics propis de les ciències, com ara els congressos científics i els pòsters científics, el que suposa una oportunitat per a treballar aspectes procedimentals (analitzar dades i comunicar-les, treure conclusions i defensar-les) i epistèmics (construir coneixement en comunitat, separar el que són dades del que són interpretacions o conclusions...) treballant la connexió de llengua i ciència (DomènechCasal, 2016).

Al mateix temps, també elements propers i que formen part de la vida quotidiana dels joves, com els telèfons mòbils són eines potents per al treball científic que ja haguessin volgut per a ells els astronautes que van anar a la Lluna. Per què no aprofitar aquesta tecnologia per a desenvolupar la part experimental de les matèries de ciències?

\section{DESCRIPCIÓ D’EXPERIÈNCIES}

\section{Simposi Internacional sobre Sismes (Marcel Costa)}

La proposta didàctica s'inicia amb un text que presenta l'encàrrec a 24 alumnes de 4t d'ESO de I'INS Castellar (Castellar del Vallès): la presentació d'un pòster a un simposi internacional de sismologia. Cada grup de 4 alumnes rep un encàrrec diferent que consisteix en analitzar un sisme històric concret per esbrinar-ne les seves causes i conseqüències, i valorar si s'hagués pogut aplicar alguna mesura preventiva. Cadascun dels sismes és representatiu d'un tipus diferent de contacte de plaques, de manera que, en el seu conjunt, es tracten una part important dels continguts curriculars relacionats amb la geodinàmica interna de la Terra. Cada encàrrec disposa de recursos web i bibliogràfics on cercar informació, així com una breu pauta dels continguts i apartat que, com a mínim, ha d'incloure cada pòster.

Els alumnes van dedicar dues sessions i mitja a l'elaboració dels pòsters. La sessió de presentació dels pòsters es va realitzar al vestíbul de l'institut per a poder disposar d'un espai més ampli. Durant aquesta sessió, cada grup s'havia d'organitzar de manera que sempre hi hagués algun dels seus membres (rol "d'informador/a") per anar explicant els continguts del seu pòster als altres grups d'alumnes que hi anessin passant, així com aclarir-los aquells dubtes que els plantegessin. Mentrestant, els altres membres del grup havien d'anar revisant els pòsters d'altres grups (rol de "cercador/a" d'informació) i anotant els continguts més rellevants en un full de síntesi. Aquests rols eren rotatoris o bé fixos a criteri del grup

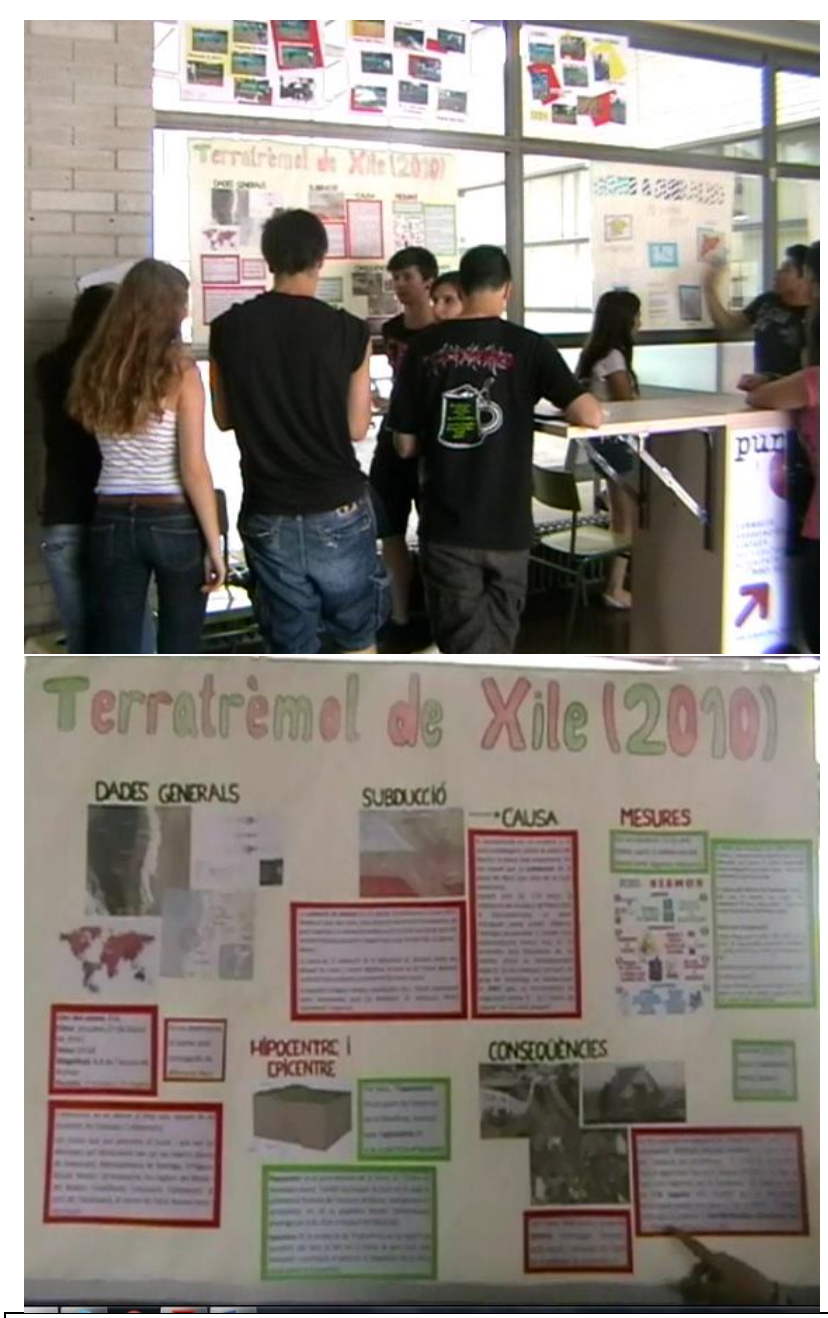

Figura 1. Grup d'estudiants de 4t d'ESO de l'INS Castellar durant la realització de la sessió de pòsters al vestíbul del centre.

La sessió de classe posterior a la presentació de pòsters es dedicà a fer la posada en comú a nivell de cada grup del total d'informació presentada al simposi i a aclarir els dubtes sorgits a partir d'una activitat de regulació. Durant la sisena i darrera sessió de la seqüència es realitzà una prova escrita sobre els continguts treballats. Aquesta prova consistia en diverses preguntes contextualitzades que requerien l'aplicació dels principals continguts tractats al llarg de la seqüència.

L'avaluació d'aquesta seqüència didàctica es realitza a partir d'una prova escrita (posteriorment a la qual es feia una activitat de regulació) i de dues rúbriques, accessibles per a la seva descàrrega [1]:

- Disseny i continguts de pòster a partir d'una rúbrica (coavaluació entre grups i avaluació per part del docent). 
- Coavaluació entre alumnes dels rols d'informador/a i cercador/a d'informació a partir d'una rúbrica.

\section{Fem del mòbil un laboratori de Física (José Luis Touron)}

Aquest projecte sorgeix d'una pregunta que ens hem fet a classe: Què haguessin fet Galileu, Newton o Einstein d'haver tingut un smartphone? I totes les que d'ella es deriven. A partir d'aquí es desprenen moltes possibilitats de treballar tot el currículum de Física tant a l'ESO com a batxillerat. En el nostre cas l'hem desenvolupat a l'escola Virolai en el marc de la Unitat sobre moviment a l'assignatura de Física de $1 r$ de Batxillerat, i aplicat amb 35 alumnes organitzats en 11 grups de 3 o 4 alumnes. Els materials del projecte es poden consultar a: https://sites.google.com/virolai.com/iphysics.

El projecte consisteix en fer una recerca de les possibilitats que ofereixen els smartphones com a eina de mesura, enregistrament i/o anàlisi de dades per a dissenyar experiments que posin a prova les lleis de la natura que estudiem a classe utilitzant l'smartphone en alguna de les fases de l'experiment. Els estudiants es van organitzar en equips de quatre o cinc alumnes i vam fer una primera sessió on vam establir el calendari de treball, que va quedar fixat en 8 sessions d'una hora per setmana destinades, principalment, a exposar les propostes i discutir de manera grupal les millores que es podien fer i els inconvenients que s'havien de superar. La tasca que va quedar pendent per a la següent sessió va ser la recerca de les característiques dels mòbils (sensors, apps disponibles, etc.) per a ser exposades entre tots i arribar a un coneixement exhaustiu de les possibilitats que tenien els nostres dispositius. A partir d'aquí, cada grup va decidir quin tipus d'experiment desenvoluparia i vam establir entre tots què voldríem com a producte final. Finalment, vam decidir que el producte final seria un article científic i un vídeo tutorial de l'experiment així com el compromís de presentar-ho a la fira de ciències de l'escola. Una vegada van quedar determinades les condicions dels productes finals, vam consensuar la rúbrica amb què serien avaluats els treballs. En la rúbrica (disponible a la web del projecte) es consideren aspectes com el disseny experimental, claredat dels conceptes, participació en les jornades de discussió conjunta i qualitat del producte final.

Entre els treballs van haver-n'hi alguns que utilitzaven el mòbil com eina d'enregistrament de vídeo d'objectes en moviment, per a després utilitzar el programa Tracker [2] com eina d'anàlisi de dades per trobar l'acceleració o les gràfiques de posiciótemps. Altres grups van utilitzar l'acceleròmetre per mesurar l'acceleració de la gravetat o per enregistrar l'acceleració centrípeta d'un moviment circular, etc.

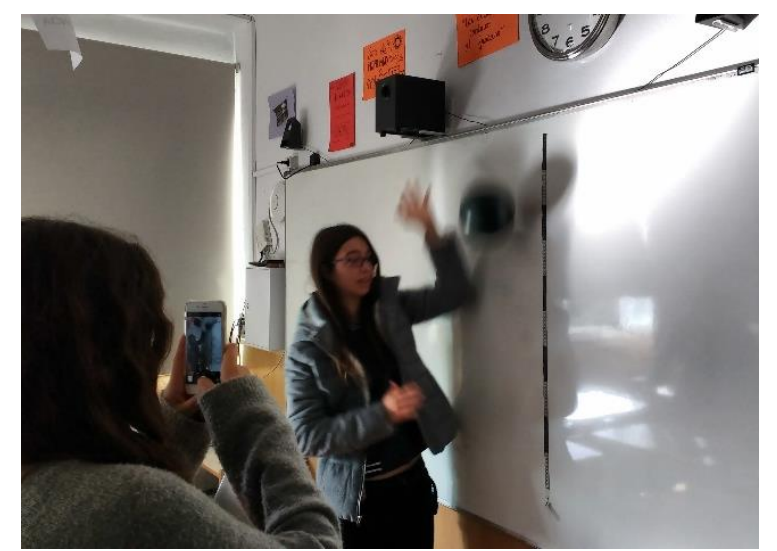

Figura 2. Alumnes fan servir els seus smartphones per a realitzar experiments de física a l'aula.

\section{Estudi del paisatge per descobrir-ne els detalls que el fan característic (Albert Arcas)}

Partint de l'observació científica i la recollida de dades en l'estudi dels diferents ecosistemes a l'entorn del centre, es planteja un treball des de diferents àmbits en el que els alumnes elaboren un producte final en forma de pòsters científics, que recullen l'estudi del biòtop a nivell de clima, terreny (Ciències Socials i Geologia) i de la biocenosi (Biologia). Aquest producte final es presenta i s'exposa públicament en un espai municipal, fet que permet treballar aspectes relatius a la comunicació científica en català i anglès (Àmbit Lingüístic) i l'art (Visual i plàstica).

Aquest projecte s'ha realitzat en dues ocasions i en dos formats de productes finals força diferents. Sempre partim del fet que un projecte ha de ser viu i contemporani, per tant ha de tenir la capacitat d'evolucionar any rere any. Els materials es troben disponibles als webs: https://sites.google.com/a/institutsantpol.cat/trencaclosques-viu/ i https://sites.google.com/institutsantpol.cat/paisatges.

S'organitza l'alumnat en grups i, després d'haver comunicat els objectius d'aprenentatge, se'ls assigna un rol de coordinació diferent a cada membre del grup: Coordinació Documental (Procurar per la qualitat dels conceptes científics i geogràfics); Coordinació Lingüística (Procurar per la qualitat dels textos presentats); Coordinació Artística (Procurar per la qualitat dels productes artístics-dibuixos, fotografies i edició GIMP); Coordinació Exposició (Procurar la publicitat de l'exposició a totes les poblacions, patrocinadors, convidar personalitats,...). 
El treball s'estructura en 3 setmanes. L'alumnat inicia el seu treball a partir d'unes coordenades geogràfiques, relacionades amb alguna població mundial que havia de descobrir. Aquest és l'origen del seu equip de recerca. Això els porta a estudiar el clima d'aquesta regió mundial durant la primera setmana i comparar-lo amb el model del clima que se'ls havia donat fet. Finalment, s'acaba realitzant un pòster científic climàtic. Durant la segona setmana es realitza una sortida de camp per a l'estudi d'observació de la fauna existent a l'entorn de l'Institut. Cada grup de recerca realitza la descripció i representació dels organismes propis dels ecosistemes de l'entorn (bosc, fluviotorrencial, urbà, litoral,...).

Per a fer les diverses tasques, es proporcionen als alumnes bastides i rúbriques d'orientació.

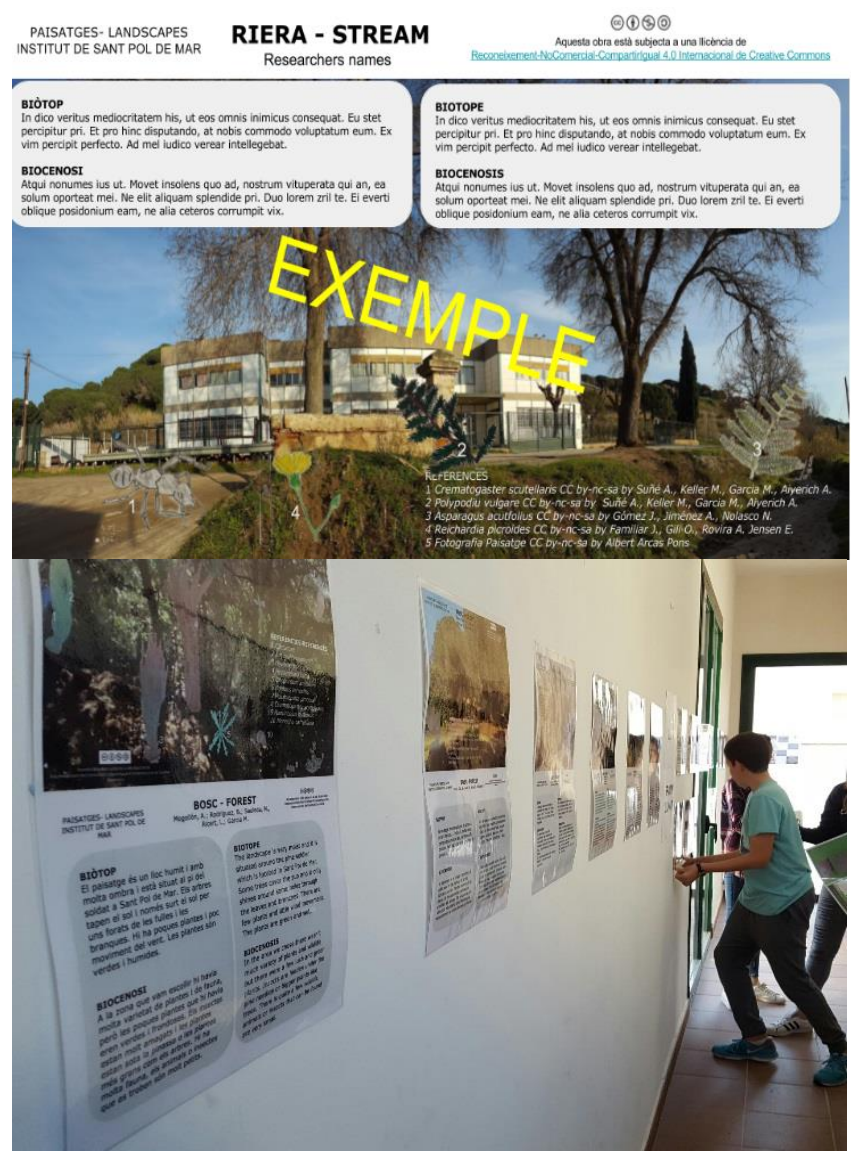

Figura 3. a) Plantilla per a la creació d'un pòster científic. b) Imatge de l'exposició de pòsters.

Finalment, la tercera setmana es prepara i es realitza l'exposició. Aquesta es publica digitalment i es presenta i s'obre al poble. Així l'alumnat pot aprofitar per presentar els aprenentatges als visitants.

Al llarg del projecte, l'alumnat s'autoavalua diàriament el seu treball $\mathrm{i}$ al final del projecte en consens amb el grup, amb l'ajut de diverses rúbriques. L'avaluació dels treballs realitzats la realitza el professorat especialista de la matèria i l'expressió oral i escrita, el professorat de llengües el dia de l'exposició. Les rúbriques usades són disponibles al lloc web de l'activitat [3].

Tot i que l'estructura de treball de recerca científica segueix un protocol molt establert, el caire que se li vulgui donar a l'exposició, pot servir a gran diversitat de competències, ja siguin de l'àmbit més científic, artístic, lingüístic, etc.

\section{Plastic Zero (Quique Vergara)}

Plàstic Zero és una experiència dels alumnes de 3r d'ESO del Col-legi Maristes Champagnat treballant en col•laboració amb l'Institut Enric Borràs de Badalona en el marc del projecte observadors del mar: un projecte de ciència ciutadana de recerca marina impulsat per l'Institut de Ciències del Mar de Barcelona (CSIC). La tasca es va encomanar des de la matèria de Física i Química de 3r d'ESO i hi van participar un total de 86 alumnes.

La proposta didàctica neix al voltant de la presència de microplàstics a la platja de Badalona i s'emmarca dintre dels blocs de l'activitat científica i a la matèria del currículum de Física i Química de $3 r$ d'ESO.

Els objectius d'aprenentatge són els següents:

- Estudiar propietats dels polímers.

- Valorar la ciència com a part important de la societat integrada en la mateixa, especialment pel que fa a la química.

- Fer propostes reals per incidir en la problemàtica estudiada, donant alternatives a l'ús de bosses de plàstic.

El projecte fou breu (2 mesos, amb una durada entre 10 i 20 hores lectives), dut a terme entre els mesos de febrer i abril del 2016, fomentant el treball autònom del grup classe, amb una configuració d'aula en grups de quatre alumnes, només amb un suport puntual dels científics i que segueix la següent seqüència:

1) Llançament: Seqüència didàctica del projecte EngagingScience [4] sobre la problemàtica de les bosses de plàstic, presentació de la problemàtica.

2) Acord de la metodologia de treball de camp pel que fa al mostreig i el treball de laboratori de manera conjunta amb professors i científics. En aquesta fase es treballa de manera especial la idea de l'aplicació de ciència, control de variables 
pel mostreig i altres aspectes rellevants del treball científic, amb el recolzament d'un protocol de mostreig [5].

3) Realització del treball de camp i anàlisi de laboratori. Es realitzen dos mostrejos a la platja de Badalona dividint seccions de la platja per grups. En un dels mostreigs assisteixen els científics col-laboradors per tal d'ajudar en l'acompanyament dels alumnes (Figura 5a). Amb les mostres obtingudes es procedeix a determinar les quantitats de micro i macroplàstics existents a la zona definida.

4) Tractament dels resultats, discussió en grup classe i compartir els mateixos a la plataforma d'observadors del mar [6].

5) Realització d'un congrés científica l'escola d'exposició de resultats mitjançant la preparació i comunicació d'un pòster científic amb el projecte realitzat. Posteriorment, les escoles participants presenten els seus resultats al Cosmocaixa de Barcelona durant la celebració del projecte $R e$ cercaixa (Figura 5b).

6) Com a tancament de l'activitat, es proposà que els alumnes treballessin en els mateixos grups per tal de fer una proposta per a reduir el consum de plàstic en algun entorn real o de reducció dels residus generats.

L'avaluació es va anar realitzant al llarg de tot el projecte mitjançant meetings amb els dos professors implicats en el projecte, de manera que es podien millorar els aspectes relatius a cada una de les fases del projecte. Es van introduir també coavaluacions entre els grups.

Com a element diferenciador d'aquest projecte, cal comentar que es va fer una avaluació externa del projecte en tres moments diferents del seu desenvolupament a través de diferents estratègies, els resultats de la qual indicaren l'eficàcia d'aquest tipus d'activitats.

\section{CONCLUSIONS}

L'avantatge principal de la metodologia ABP radica en la motivació que produeix treballar amb l'objectiu d'obtenir un producte final que ha de ser exposat públicament (Larmer, Mergendoller i Boss, 2015). La comunicació, la discussió i exposició a la crítica dels models o prototips dels experiments durant el procés de creació és un aspecte didàctic clau d'aquesta aproximació (Patton, 2012), ja que permet donar rellevància a aspectes conceptuals i de disseny experimental que no apareixerien en cas de donar als alumnes una guia de pràctica creada per l'educador on només s'hagi de seguir les instrucci- ons per a fer l'experiment. Per a garantir una participació activa de tot l'alumnat durant el procés de crítica dels models s'ha de deixar ben clar aquest aspecte a les rúbriques d'avaluació. En aquest sentit, hem vist que aportar models del treball a realitzar, rúbriques i acompanyar des de les matèries el treball que es realitza al projecte és molt important per fer significatiu l'aprenentatge.

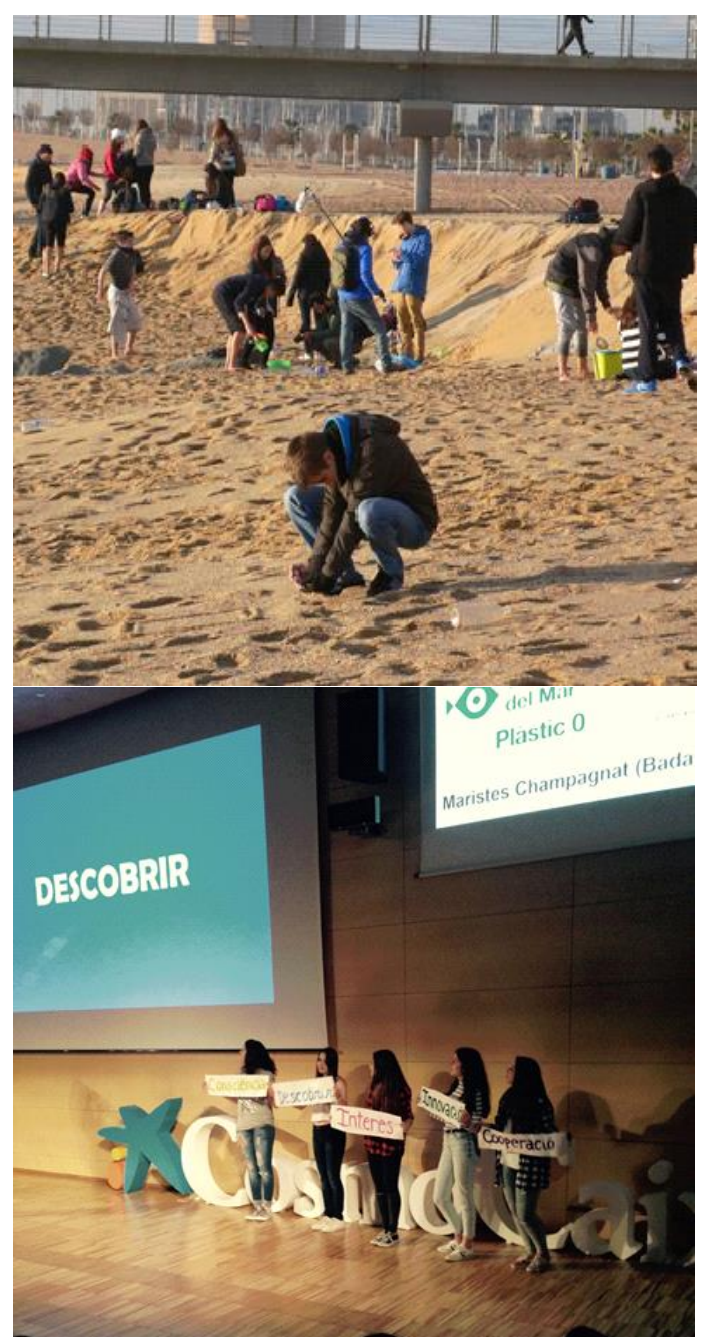

Figura 5. a) Grup d'estudiants realitzant els mostrejos a la platja de Badalona; b) Jornada presentació projecte: Paraules triades pels alumnes per definir el projecte: consciència, descobrir, interès, innovació i cooperació

De manera general, hem detectat que en avaluar l'aprenentatge de continguts de ciències, detectem que són capaços d'incorporar-los i transferir-los a altres qüestions proposades. En especial, hem detectat que es desenvolupen competències científiques, comunicatives i TIC.

Escollir formats de comunicació científics (pòsters, simposis, seminaris a l'aula,...) ha resultat ser 
una manera activa de portar a l'aula el discurs procedimental i epistèmic de les ciències.

Aquestes activitats tenen un efecte important en la motivació dels alumnes i convé cuidar la part formal i publicitària de l'acte per a dignificar la seva feina. En aquest sentit, l'organització de simposis, congressos, de forma interna al centre o oberta a l'exterior, són un espai amb moltes possibilitats.

\section{AGRAIMENTS}

Aquest article recull el contingut de les ponències de les Jornades sobre Aprenentatge Basat en Projectes \#STEMABP [https://stemabp.wordpress.com/], organitzades pel CESIRE del Departament d'Ensenyament i la Fundació Catalana per la Recerca i la Innovació. Els autors agraïm al professorat i alumnat dels centres la seva participació i a Jordi Domènech la tasca d'edició de l'article.

\section{BIBLIOGRAFIA}

ARCAS, A., ROVIRA, B. (2016). Site $i$ conclusions del projecte International scientific congress "invassive organisms". [https://sites.google.com/a/institutsantpol.cat/trencaclosquesviu/treball/conclusions]

CLAXTON, G. (1994). Educar mentes curiosas. Ed. Visor (Aprendizaje).Madrid.

DOMÈNECH-CASAL, J. (2016). Proyecto C3: indagación científica, lengua y contextos en la ESO. Aula de Secundaria, 19, 15-19.

GRAU, R. (2010). Altres formes de fer ciències. Alternatives a l'aula de secundària. Ed. Associació de Mestres Rosa Sensat. Col•lecció Premis, 7.

LARMER, J., MERGENDOLLER, J., BOSS, S. (2015). Setting the Standard for Project Based Learning. ASCD, 2015.
PATTON, A. (2012). Work that matters: The teacher's guide to project-based learning. Paul Hamlyn Foundation, London

\section{NOTES}

[1] Rúbrica per al Simposi: https://stemabp.files.wordpress.com/2017/04/criteris-avaluacic3b3-simposi.docx;

Rúbrica per als Pòsters:

https://stemabp.files.wordpress.com/2017/04/criteris-avaluacic3b3-pc3b2sters.docx

[2] Programa Tracker: Tracker Video Analysis and Modeling Tool:

http://physlets.org/tracker/

[3] Rúbriques d'avaluació del Scientific Congress of Invasive Organisms:

https://sites.google.com/a/institutsantpol.cat/trencaclosques-viu/avaluacio

[4] Materials Engaging Science: https://www.engagingscience.eu/es/2015/02/17/el-fin-de-las-bolsas-deplastico/

[5] Protocol de Mostreig d'Observadors del Mar: https://drive.google.com/drive/u/0/folders/0B6wNNpquPe0edjlHajZ2ankwYWs

[6] Protocol de participació a Observadors del Mar: http://www.observadoresdelmar.es/que-es.php

[7] Informe complet. Impacte de la introducció de la Ciència Ciutadana a les Escoles dins el projecte Ciència Ciutadana: Educació i Recerca, del programa Recercaixa: https://cciutadana.files.wordpress.com/2016/05/cic3a8nciaciutadana-recercaieducacic3b3_v5.pdf 